\title{
حق الضيف في حديث الجائزة
}

د ـ لبنى حسن عذيب / جامعة واسط / كلية التربية / قسم علوم القران

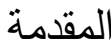

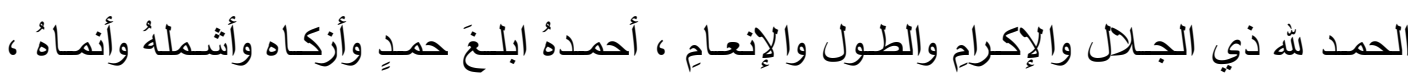

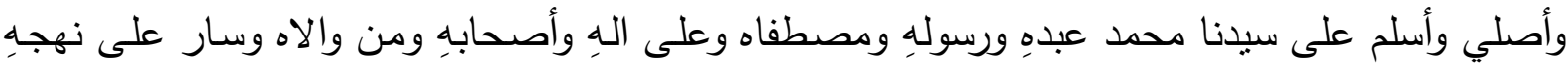
واهتدى بهداه إلى أن يبلغ الدهر منتهاه .

أمسا بعد فـإن موضـوع بحثي هذا هو ( حق الضيف في حديث الجـائزة ) وممـا لا ريب أن

موضوع الضيافة واسـع جداً ، لكن في بحثي هذا ركزت على معنى الجائزة ، وهل هي واجبـة أم لا ؟ وكذلك المقصود من الأيام الثالاثة في الضيافة ، وهل هي واجبة ام لا ؟ وذللك حسب الخطة الآتية :

كلمة الضيف في المعاجم اللغوية ، والنية ، وحقوق الضيف ، وواجباته ، وبعض من الأحاديث

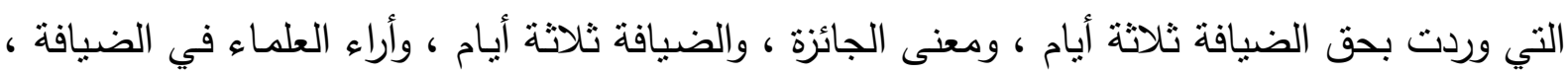

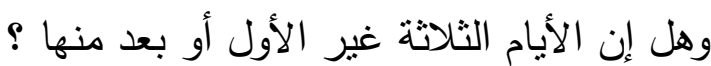

وخاتمة تضمنت نتائج هذا البحث القصير ، وفهرست تضمن المصادر والمراجع التي استعنت

هذا ولله الحمد والثناء ، وأخر دعوانا ان الحمد لله رب العالمين .

كلمة الضيف في المعاجم اللغوية

$$
\text { ضيف : ضفت الرجل ضيفاً وضيافة. }
$$

تضيفته : نزلت به ضيفاً، وملت إلبه ، وقيل: نزلت به ، وصرت وصله له ضيفاً.

ضفته ، وتضيفته : طلبت منه الضيافة .

قال شمر : سمعت رجاء بن سلمة الكوفي يقول : ضيفته إذا أطعمته، قال : والتضيف الإطعام

قال ابو الهيثم : أضـافه وضـيفه، عندنا بمعنى واحد ، كقولك : اكرم الله وكرمسه ، وأضـفته

والضيف : للواحد والجمع ، وقد يجمع على أضياف ، وضيوف (1) .

وفي التزيل العزيز قوله تعالى : "هل أناك حديث ضيف إبراهيم المكرمين" (r).

اما الضيف في المعجم الفقهي : فهو النازل عند غيره بدعوة او بدون دعوة (r). 
تتضح النية من خلال دخول الضيف على المضيف بالرزق والبركة ، سواء أكان ضيف رحماً

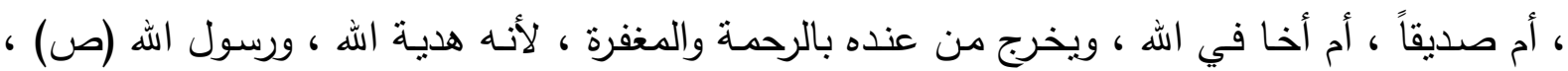

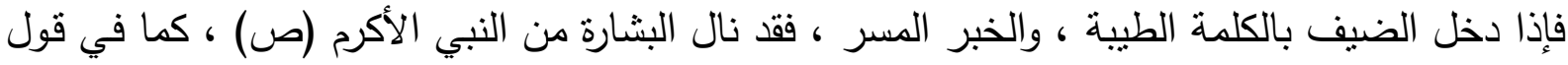

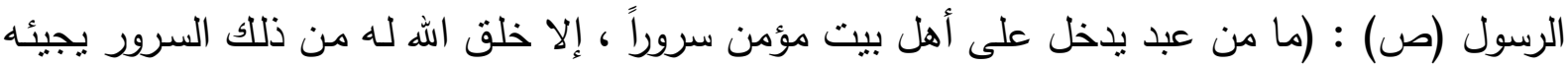

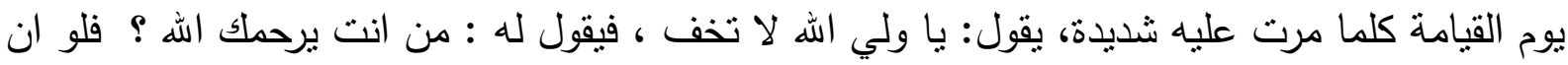

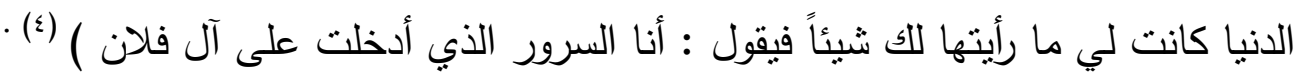

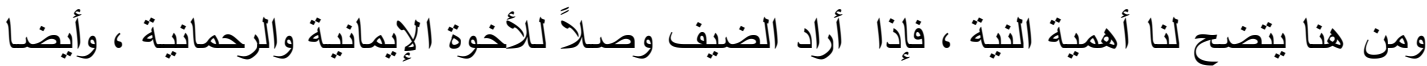

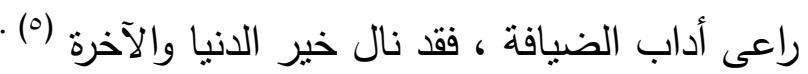
ولا شك ان ضيافة المؤمن ترجمة لحبه إلى أخيه في الله، كما في قول الرسول (ص) : (أضف الضف

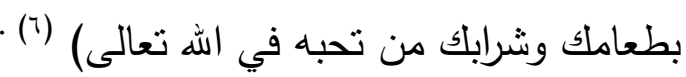
ولا بد أن يكون إلى جانب هذه النية عمل ، فهي أساسه فإذا كان العمل يخلو من النية السليمة ،

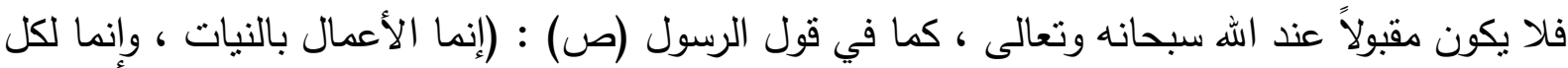
امرئ ما نوى ، فمن كانت هجرته إلى الله ورسوله ، فهجرته إلى الله ورسوله ، ومن كانت هجرته إلى دنيا

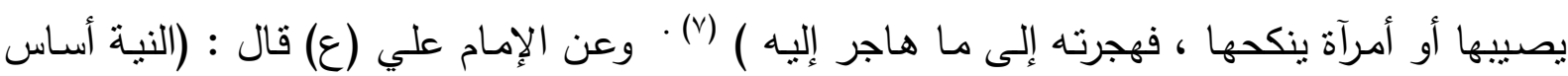

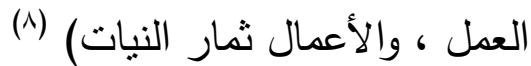

لذا فالعبد يثاب على صالح نيته ، وإن قصر عمله ، كما قال النبي (ص) : (نية المؤمن خيرٌ

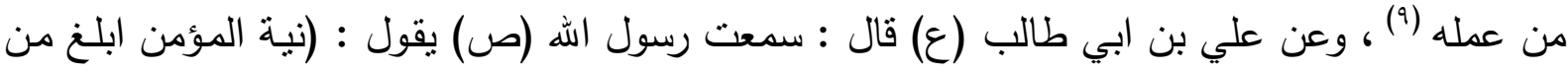

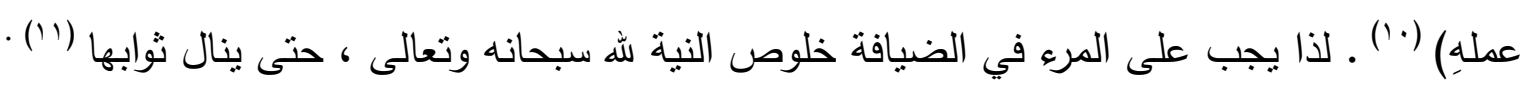
حقوق الضيف 1- دعوة المؤمنين : ففي لقائهم وضيافتهم تتعقد مجالس الذكر ، ويدور الحديث غالباً في طاعة الها سبحانه وتعالى ، وأيضا دعوة الأغنياء والفقراء معاً. r-حسن الاستقبال : يكمن هذا بطلاقة الوجه ، وطيب الكلام عند استقبال المضيف لضيفه، وهذا والهاء

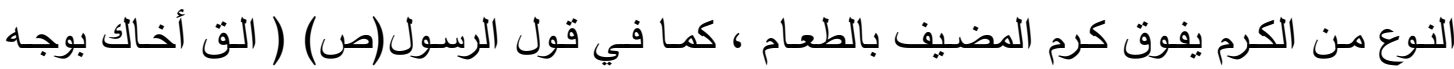

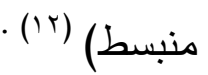
r- رفع الحرج والعناء عن الضيف ، وإفساح مجال الراحة له حتى يشعر كأنه في بيتهِ .

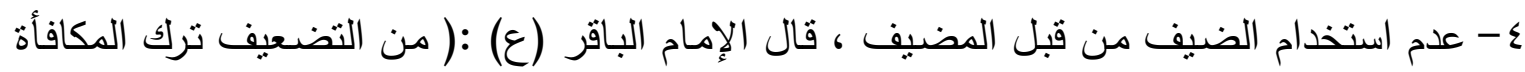

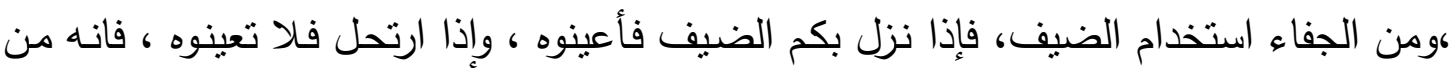


النذالة، وزودوه، وطيبوا زاده، فإنـه من السخاء) (r') ـ أي اذا نزل يعان ، ولا يعان على رحيله ،

$$
\text { وليزود وبطيب زاده (ع () . }
$$

ه-ترك التكلف بطلب من الضيف (10) ، كما في قول الرسول (ص) : ( لايتكلفن احد لضيفه مالا

$$
\text { يقدر ) (17) نرك }
$$

وقد كره جماعة من السلف التكلف للضيف، وهو محمول على ما يشق على صاحب البيت مشقة ظاهرة ، لان ذلك يمنعه من الإخلاص ، وكمال السرور بالضيف ، وربما ظهر عليه شيء من ذلك

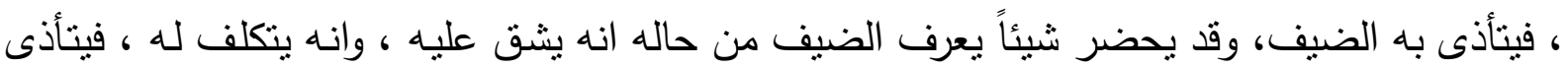
الضيف لثفقته عليه، وكل هذا مخالف لقوله (ص) : (من كان يؤمن باله واليوم الأخر، فليكرم ضيفه)

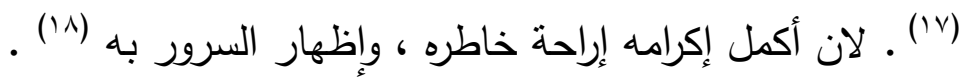

أمـا حقيقة الترابط بين الإيمـان والإكرام ، فالإيمـان بعني الإيمـان الكامل ، وخصسه بـاله واليوم الآخر إثـارة إلى المبدأ والميعاد، اي ان من أمن بـاله الذي خلقه، وأمن بأنه سيجازيه بعمله ، فليفعل الإن الخصال المذكورات ، التي من ضمنها إكرام الضيف ، وهذا الإكرام يختلف باختلاف الأشخاص والأحوال ، فقد يكون فرض عين ، وقد يكون فرض كفاية ، وقد يكون مستحباً، ويجمع الجميع على انه من مكارم

ج- أن يعجل المضيف في إحضار الطعام للضيف ،خمسة يعجل بهن ، فهن من سنة رسول الله

(ص) : (إطعام الضيف ، وتجهيز البيت ، وتزويج البكر ، وقضاء الدين ، والتوبة من الذنوب) (·r) . - خدمة الضيف بنفس المضيف ، فان هذا تعبير عن التواضع ، وفيه ثواب عظيم كما في قول الرسول (ص) : (أيما مسلم خدم قوماً من المسلمين إلا أعطاه الله منل عددهم

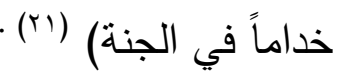

^- يستحب الأكل مع الضيف ليلقي الحثمة (rr) ، فالمواكلة سنة شريفة ينقلها الإمام الصادق(ع) في قوله: (كان رسول الله (ص) إذا أكل مع القوم أول من يضع يده مع القوم، وأخر

$$
\text { من يرفعها إلى أن يأكل القوم) (rr) . }
$$

9- قلة النظر إلى الضيف وهو منشغل بتناول الطعام (؟؟) .

$$
\text { واجبات الضيف }
$$

1- مراعاة الآداب الثرعية ، وذلك بترك كل عمل وقول لا يرضاه الله سبحانه وتعالى، فحينما يقدم زائراً على أخيه المؤمن يقدم الموعظة ، أو النصيحة ، أو يستمع إليها، لا أن يأني لكي يستمع لئح 
لأخبار الناس ، ويتجسس على مثالبهم، او حتى التجسس على مضيفِهِ نفسـِه، وهو الذي يقوم بإكرامه. r- أن لا يتصدر الدار ، ولا يقصد أحسن الأمساكن ، وعليه أن يترك الخيار في جلوسـه لصـاحب

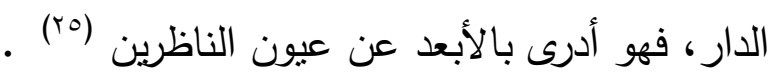
ب- الالتزام بوقت الدعوة ، فلا يتأخر الضيف لكي لا يطول انتظار المضيف أو الآخرين ، كما لا لأل ينبغي له ان يأتي عاجلاً اذا كان هنالك موعد مقرر، وبالتالي سيفاجئ المضيف بحضوره قبل الاستعداد لاد بطوة

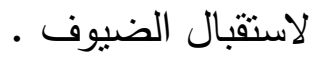

ع- التخفيف على المضيف ، بعدم إحراجه بكثرة الطلبات .

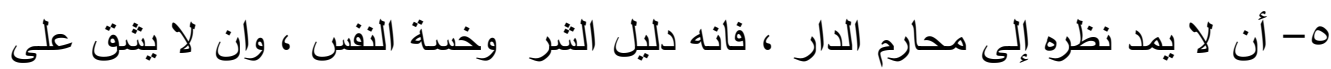
المضيف ، فينظر إلى نوع وكمية الطعام ، فأن ذلك دليل سوء نية الزيارة ، لا لصلة

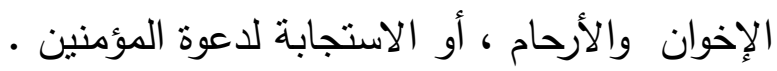
צ- حفظ أسرار المضيف ، فلا يجوز للضيف أن ينقل مـا اطلع عليه من شؤونه الخاصـة ، ومـا كتمه على الناس ، فان نقلهُ لها تُعد خيانة ، وربما كان في بعض الإفثاء هتلك للحرمات (بr) .

بعض من أحاديث الضيافة التي ورد فيها لفظ (الجائزة) أ- علي بن إبراهيم ،عن أبيه ،عن الحسن بن الحسين الفارسي ،عن سليمان بن حفص البصري ،عن أبي عبد الله (ع) قال : قال رسول الله (ص) : (الضيف يلطف ليلتين ، فإذا كانت الليلة لثالثة ، فهو من أهل البيت يأكل ما أدرك ) (rV) ץ- الحسين بن محمد ،عن معلى بن محمد ،عن واصل ،عن عبد الله بن سنان ،عن أبي عبد الله (ع) قال رسول الله (ص) : (الضيافة أول يوم والثاني والثالث ، وما بعد ذلك فإنها صدقة تصدق بها عليه قال : ثم قال (ص) : لا ينزل أحدكم على أخيه حتى يؤثثـه،قيل يـا رسول الله : كيف يؤثمه ؟ قال : حتى لا يكون عنده ما ينفق عليه ) (^^) . ז- إدريس ،عن أبيه ،عن الأشعري ،عن أبي عبد الله الرازي ،عن ابن أبي عثمان ،عن واصل،عن عبد الله بن سنان ،عن أبي عبد الله (ع) قال : قال رسول الله (ص) : ( الضيافة ثلاثة أول يوم حق ، والثاني والثالث (جائزة) ، وما بعد ذللك ، فإنها صدقة تصدق بها عليه ، ثم قال(ص) : لا ينزلن أحدكم على أخيه حتى يؤثمه ، قيل : يا رسول الله : وكيف يؤثمه ؟ قال :حتى لا يكون عنده ما ينفق عليه ) (9r). ع- عن علي بن موسى الرضـا (ع) ،عن أمير المؤمنين (ع) ، عن النبي (ص) انهه قال : (من كان يؤمن بالله واليوم الآخر ، فليكرم ضيفه ، والضيافة ثلاثة أيام ولياليهن ، فما فوق ذلك فهوصدقة ، وجايزة يوم وليلة ، ولا ينبغي للضيف أذا نزل بقوم أن بملهم ، فيخرجهم أو يخرجوه) (·r) . 
ه- حدثنا عبد الله بن بوسف ، حدثنا الليث ، قال : حدثثي سعيد المقبري ، عن أبي شريح العدوي انه قال : سمعت أذناي وأبصرت عيناي حين تكلم رسول الله (ص) فقال : (من كان يؤمن بالهه واليوم الأخر فليكرم جاره، ومن كان يؤمن بالله واليوم الأخر فليكرم ضيفه جائزته ، قيل : وما جائزته يا رسول الله ،

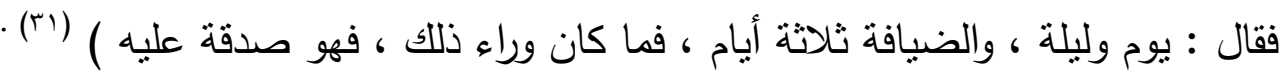
7- حدثنا عبد الله بن يوسف أخبرنا مالك ، عن سعيد بن أبي سعيد المقبري ، عن أبي شربح الكعبي إن رسول الله (ص) قال : (من كان يؤمن بالله واليوم الآخر ، فليكرم ضيفه ،جائزته يوم وليلة

، والضيافة ثثلاثة أيام ، فما بعد ذلك فهو صدقة ، ولا يحل له أن يثوى عنده حتى يحرجه) (rr) . - Vدثنا علي بن محمد ، ثنا وكيع ، ثنا سفيان ، عن منصور ، عن الثعبي ،عن المقدام أبي كريمة قال : قال رسول الله (ص) : (ليلة الضيف واجبة ، فإن أصبح بفنائه فهو دين عليه ، فإن شاء أقتضى وان شاء ترك) (r) (r)

معنى الضيافة ثناثة أيام قال العلماء : الضيافة ثناثة أيام معناه الاهتمام بـه في اليوم والليلة ، وإتحافه بما يمكن من بر وإلطاف ، وأما في اليوم الثاني والثالث ، فيطعمه ما تيسر ولا يزبد على عادته ، وأما ما كان بعد الثلاثة

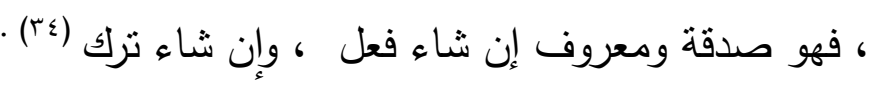
أراء العلماء في الضيافة هل هي واجبة أم لا ا-ذهب الجمهور ، ومالك ، وأبو حنيفة إلى ان الضيافة سنة ، فإذا استضـاف مسلم لا اضطرار بـه مسلما اسـتحب لـه ضيافته ، ولا تجب (ro) ، وحجـة الجمهور لفظ (جائزتـه) فـان الجـائزة هي العطية، والصلة التي أصلها على الندب وهي تقضل لا واجب ، لأنه قلما يستعمل هدا اللفظ في

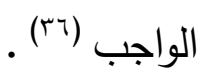
وتأول الجمهور هذه الأحاديث وأشباهها على الاستحباب ، ومكارم الأخلاق ، وتأكد حق الضيف أي منأكد الاستحباب (rv) . r- قال الليث بن سعد ، واحمد بن حنبل هي واجبة يوماً وليلة ، واحتج الليث بحديث (ليلة الضيف

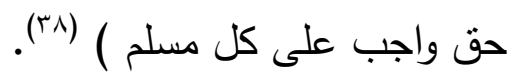
r- قال احمد : هي واجبة يوماً وليلة على أهل البادية ، وأهل القرى دون أهل المدن (جّ) ، واحتجوا بحديث أبـي شـربح *الخزاعي (رض) قـال : قـال رسـول الله (ص) : ( الضـيافة ثلاثـة أيـام ، وجائزتهـ يوم وليلة ، ولا يحل لرجل مسـلم أن يقيم عند أخيـه حتى يؤثنـهـ ، قالوا: يـا رسول الله وكيف يؤثمه ؟؟ قال : يقيم عنده ولا شئ له يقربه به) (•؛) .قال مالك، وسحنون : تجب على أهل 
البوادي ، لان المسافر يجد في الحضر المنازل في الفنادق ومواضـع النزول ، ومـا بشتري من

المأكل في الأسواق ، أما الثافعي ومحمد بن الحكم ، فذهبا على أنها واجبة عليهما معاً (1). ـ - قال ابن رسـلان : الضيافة من مكارم الأخـاق ، ومحاسن الدين ، وليست بواجبة عند عامـة

ه - قال الثوكاني : الضيافة واجبة ، واستدل عليها بدلائل عديدة ، فقال : والحق وجوب الضيافة

الأول : إباحة العقوبة بأخذ المال لمن ترك ذلك ، وهذا لا يكون في غير واجب . الثاني : التأكيد البالغ يجعل ذلك فرع الإيمان بالله واليوم الآخر ، ويفيد ان فعل خلافه ، فعل من لا يؤمن

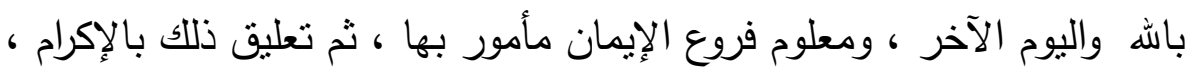

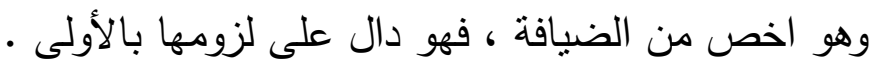

الثالث : قوله (ص) : ( فما كان وراء ذلك فهو صدقة ) ، فانه صريح ان ما قبل ذللك غير صدقة، بل واجب شرعاً. الرابع : قوله (ص) : (ليلة الضيف حق واجب ) (זّ) ، فهذا تصريح بالوجوب لم يأتِ ما يدل على تأويله ، وقوله (ص) في حديث المقام : (فإن نصره حق على كل مسلم ) (ء)؛ ، فإن ظاهر هذا وجوب النصرة ، وذلك فرع وجوب الضيافة ، إذا تقرر هذا ، تقرر ضعف ما ذهب إليه الجمهور (0؛) . 7- للشافعي رأيان إحداهما : نشترط الضيافة على الغني والمتوسط دون الفقير ، لأنه قد

يتعسر القيام بها ، والثاني : جواز الضيافة (T؛) .

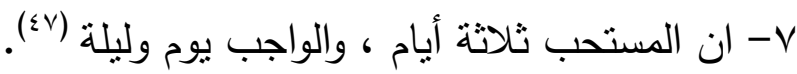

^- الضيافة المعتادة فهي واجبة لا يجب قضاؤها ، ويكون ثناثة أيام ، وإذا تكرر نزول بوله الضيف ، قيل : انها تجب في كل شهر مرة ، ولعله يعتبر العرف في تسميته ضيفاً وان قربت

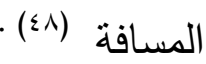

اختلف هل ان الأيام الثلاثة غير الأول أو بعد منها؟ قال ابو عبيد : يتكلف له في اليوم الأول ، وفي الثاني والثالث يقدم له ما حضره، ولا يزيد على عادته ، ثم يعطيه ما يجوز به مسافة يوم وليلة ، وتسمى (الجيزة) ، وهي قدر ما يجوز بـه المسافر من منهل الى

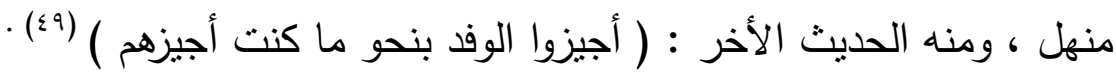
بعض الروايات تحمل الضيافة على اليوم الأخير ، كما في رواية عبد الحميد : ( الضيافة ثلاثة أيام، وجائزته يوم وليلة ) (·) ، أي قدر ما يجوز بـه المسافر ما يكفيه يوم وليلة . 
ويحتمل ان يكون المراد بقوله (ص) : (وجائزته) بياناً لحالة أخرى ، وهي ان المسافر نارة يقيم عند من

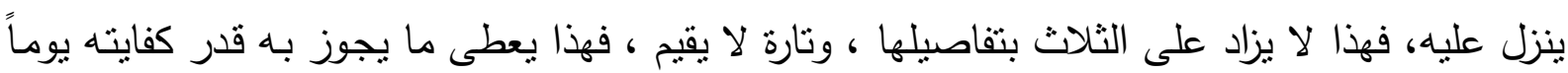

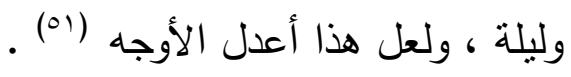

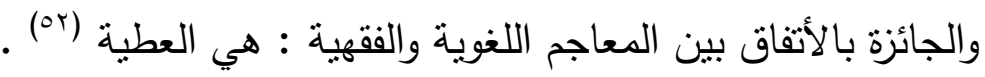

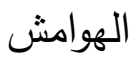

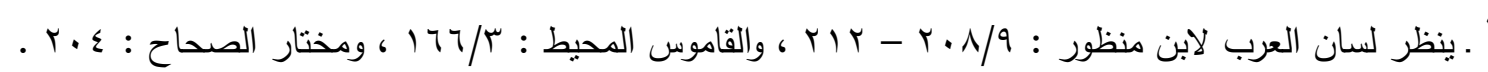

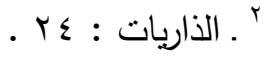

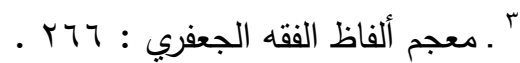

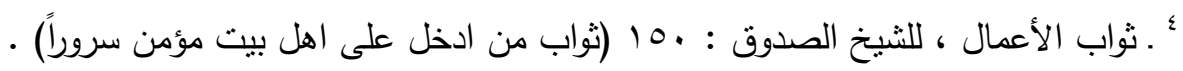

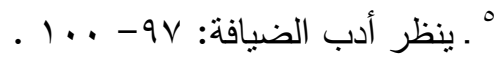

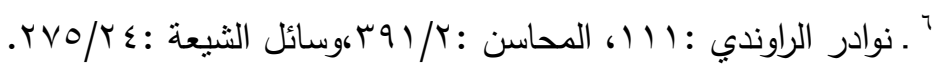

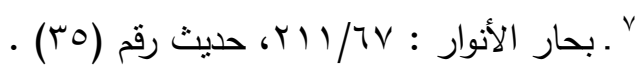

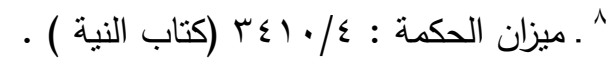

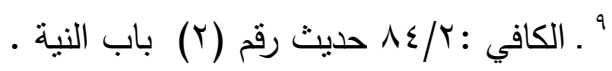

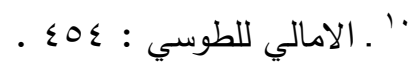

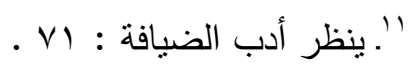

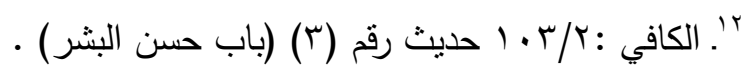

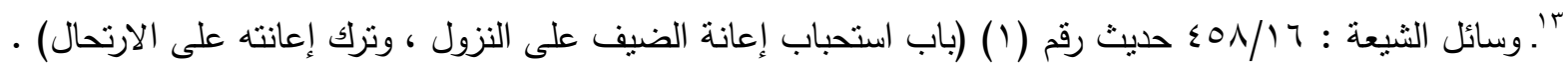

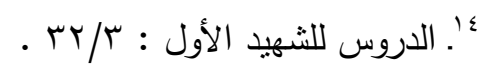

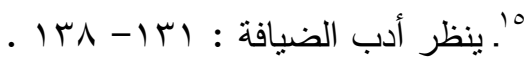

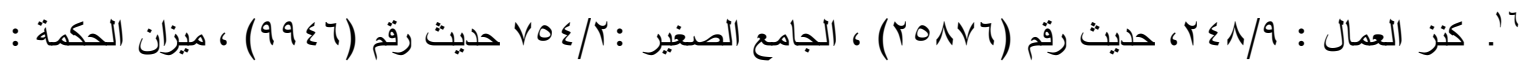

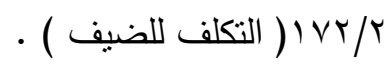

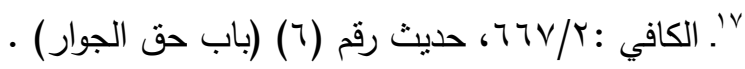

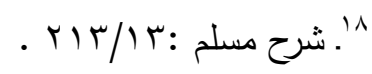

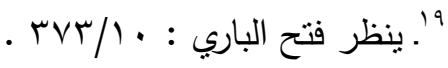

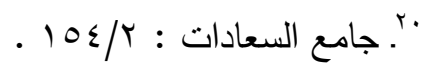

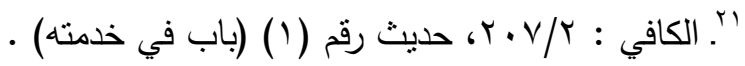

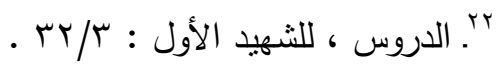

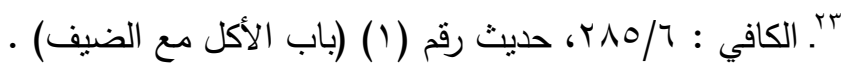
ك

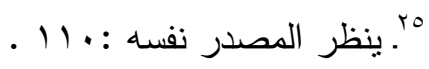




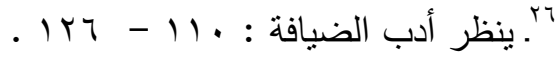

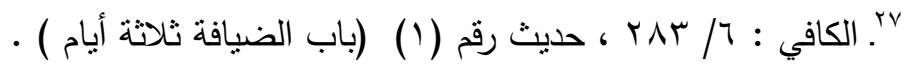

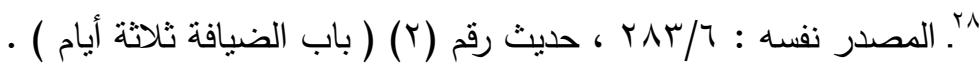

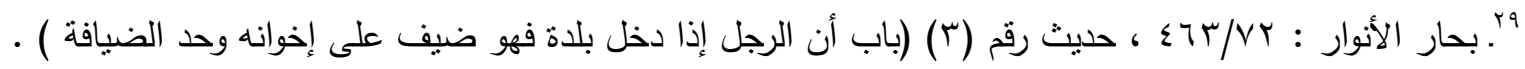

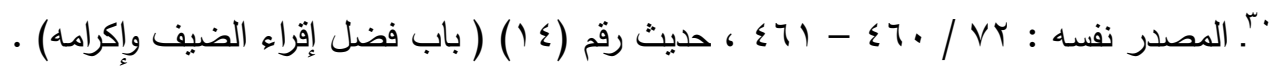

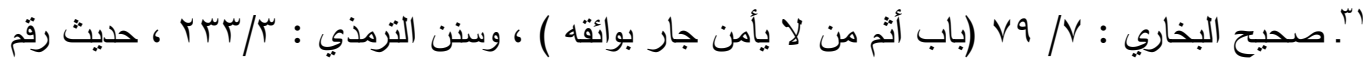

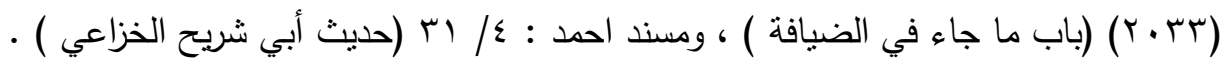

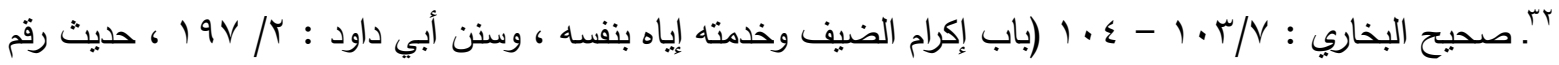
• (باب ما جاء في الضيافة ) (

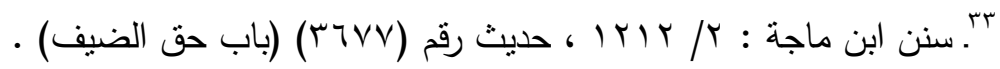

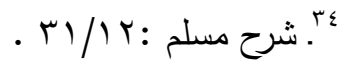
. ov/9 :

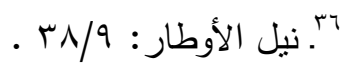

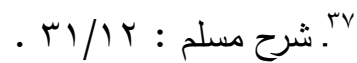

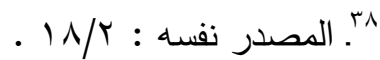

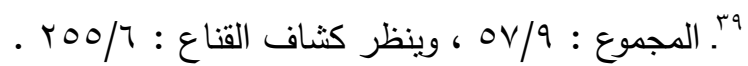

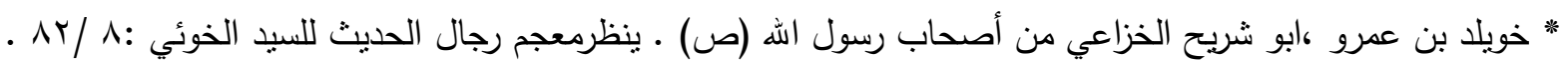

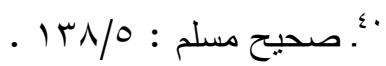

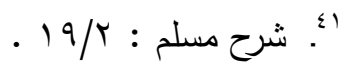

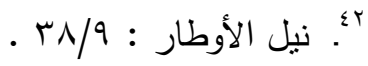

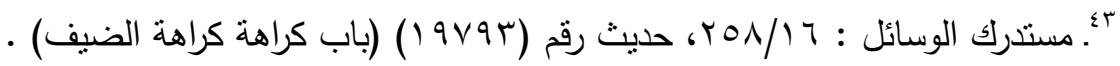

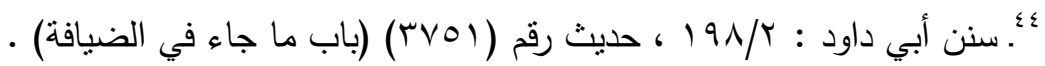

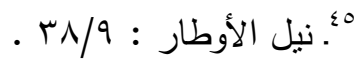

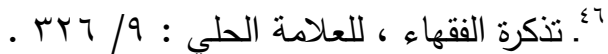

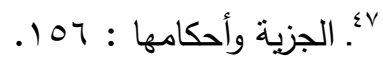

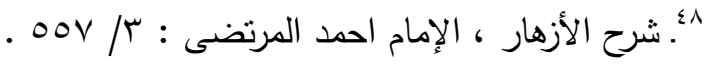

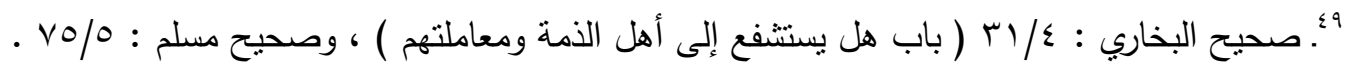

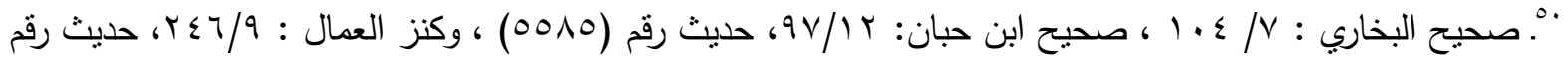

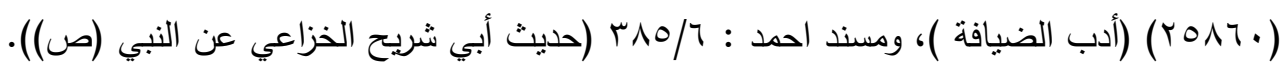

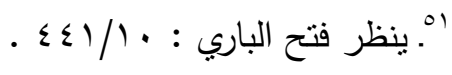

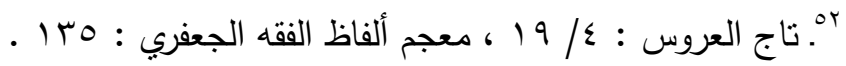


الحمد لله رب العالمين والصلاة والسلام على خير خلق الله النبي الأمين ، وعلى آله الطيبين الطاهرين ، وأصحابه المنتجبين إلى يوم الدين • - أما بعد

فأهم ما توصلت أليه في هذا البحث هو ان الضيافة مستحبة ثناثة أيام ، والواجب يوم وليلة ، وأما الجائزة فهي العطية ، وتسمى الجيزة ، وهي قدر ما يجوز به المسافر من منهل إلى منهل ، أي قدر ما

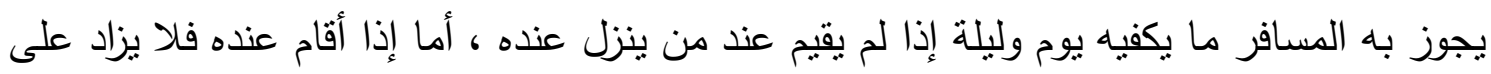

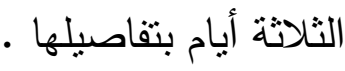
أما حديث الجائزة الذي ورد ذكره في كتاب بحار الأنوار للعلامة المجلسي ، فهو ضعيف سنداً فيه ابن ابي عثمان قال النجاشي عنه في صفحة آ7: ضعفه أصحابنا . فالحديث يعمل به من باب الأستحباب والتسامح بأدلة السنن ، لا الوجوب . والله تعالى أعلم

$$
\text { المصادر والمراجع }
$$

القرآن الكريم

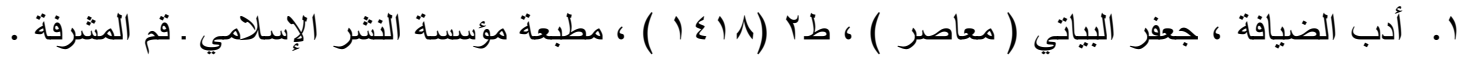

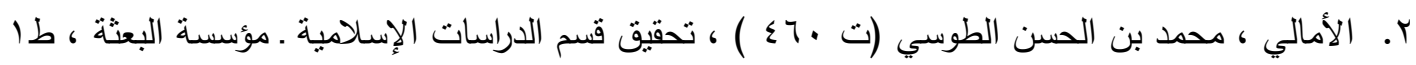

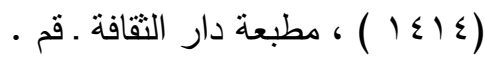

r. بحار الأنوار الجامعة لدرر أخبار الأئمة الأطهار ، للثيخ محمد باقر المجلسي (ت (1) (1) ، طب المصححة

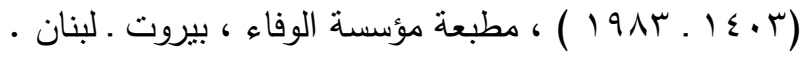

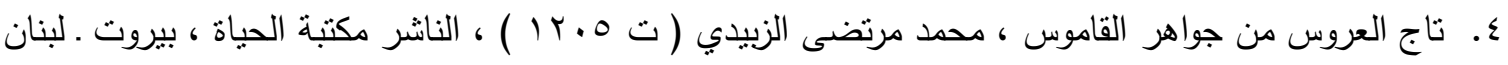




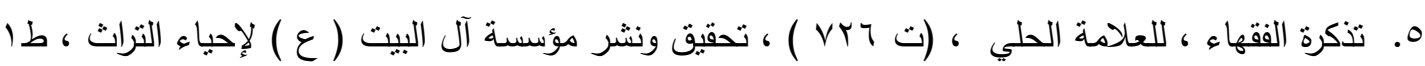

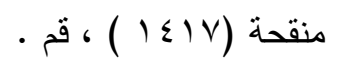

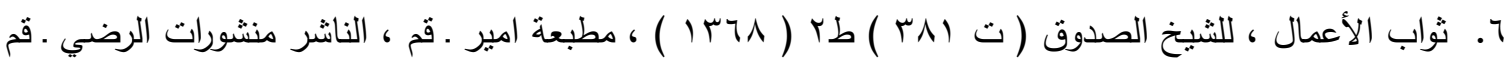

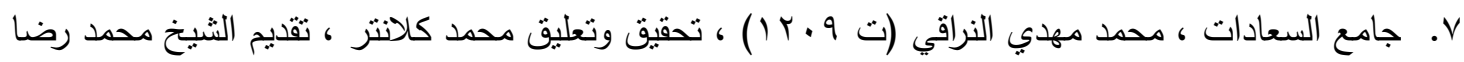

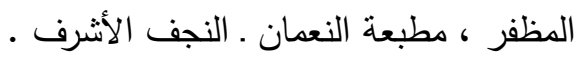
^. الجامع الصغير ، جلال الدين عبد الرحمن بن أبي بكر السيوطي (1) (9) ، طا (1 ــ (1) ، دار الفكر ، بيروت . لبنان الجعان الج

9. الجزية وأحكامها ، للشيخ علي أكبر الكلانتري (معاصر) ، طا (7 أ ( ) ، مؤسسة النشر الإسلامي .

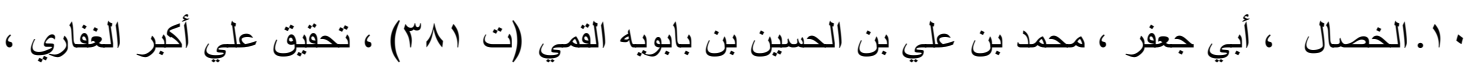

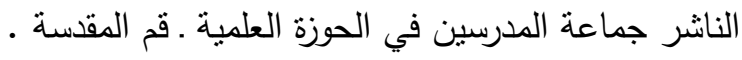

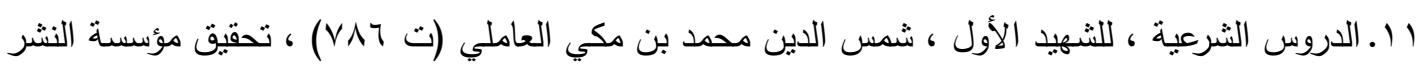

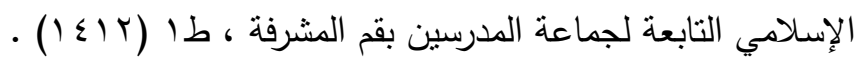

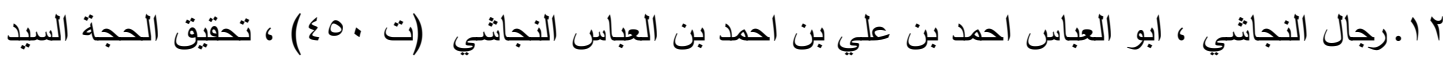

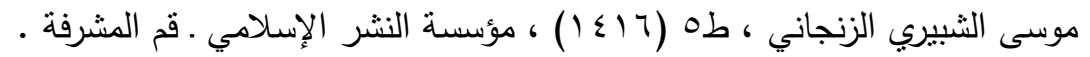

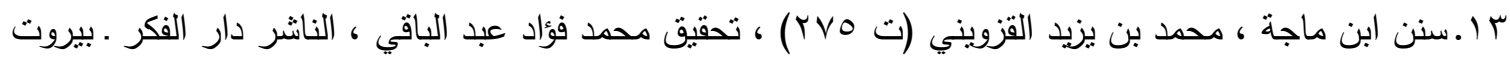

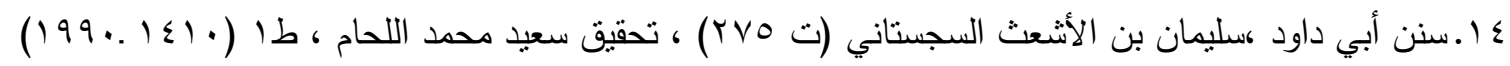
، دار الفكر • بيروت .

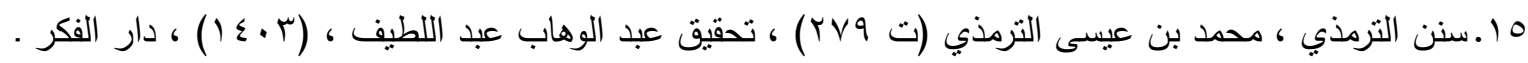
بيروت .

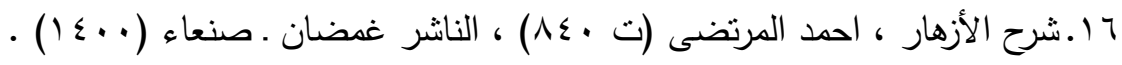

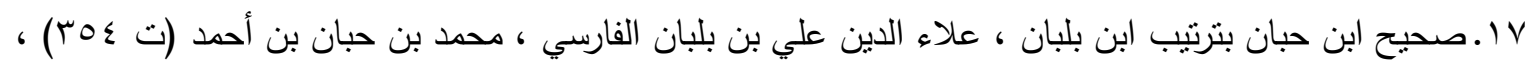

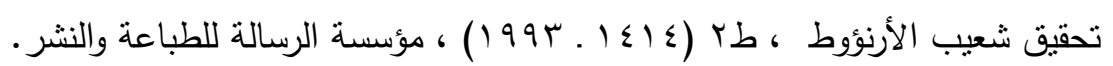

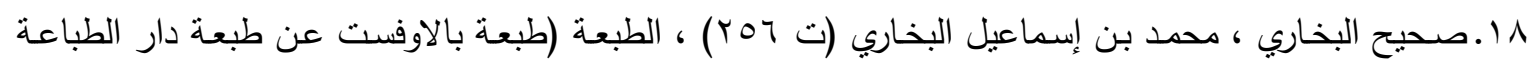

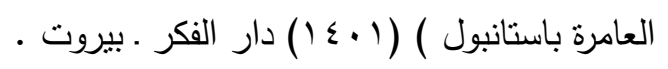

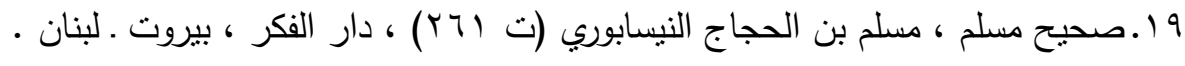

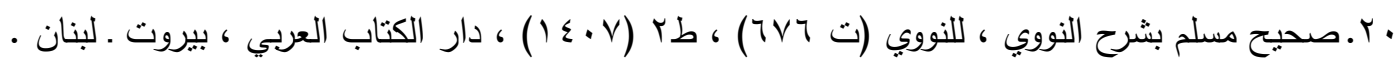

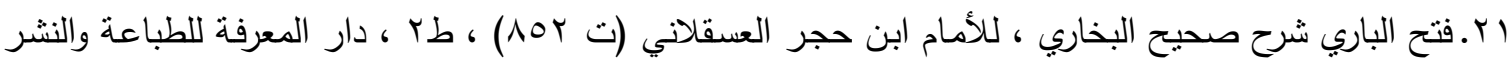
، بيروت ـ لبنان .

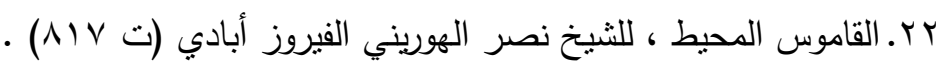

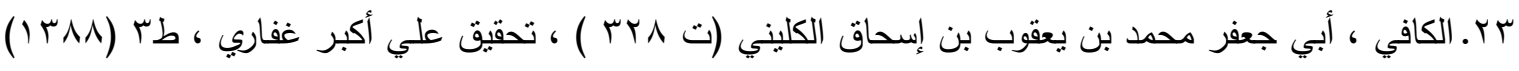

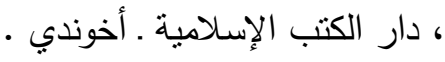




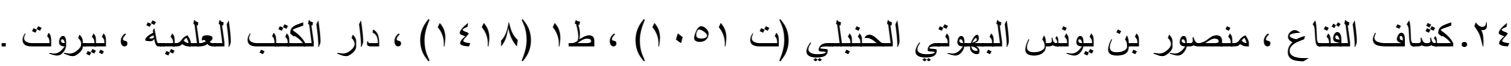

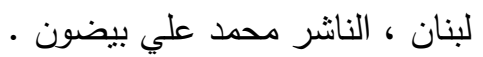

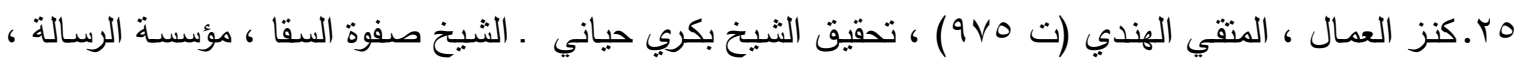

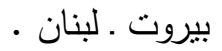

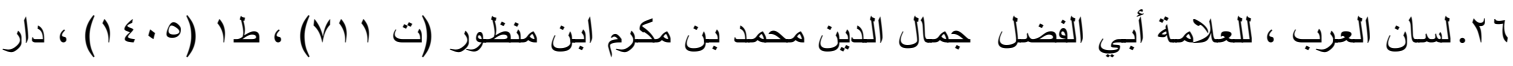

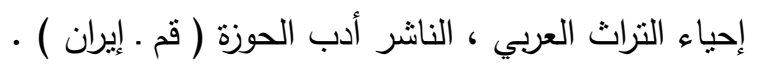

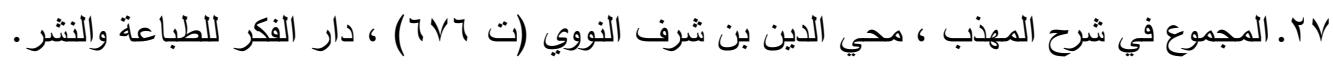

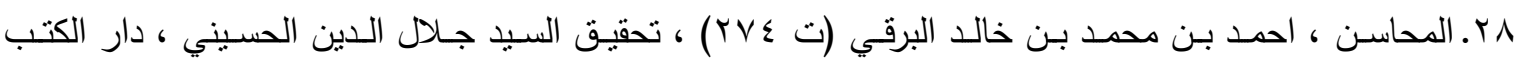

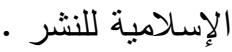

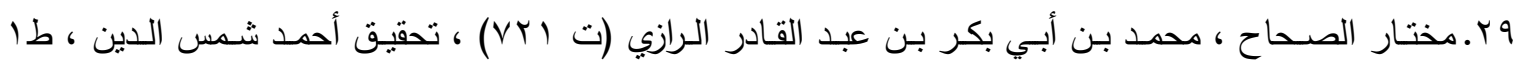

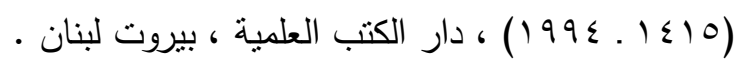

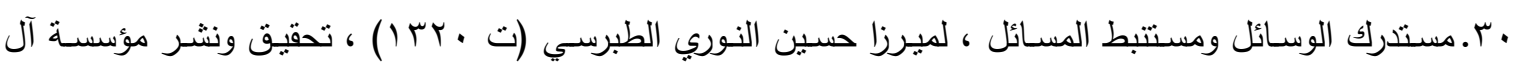

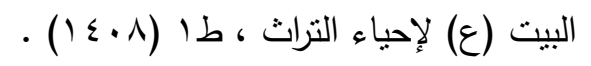

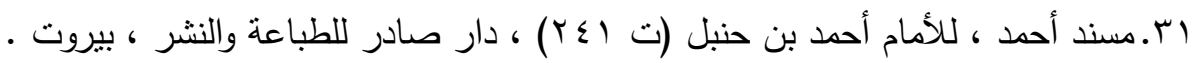

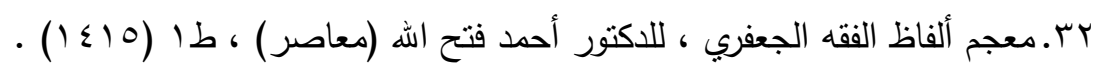

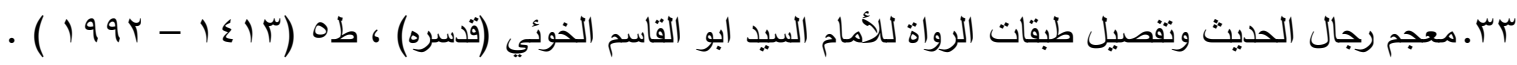

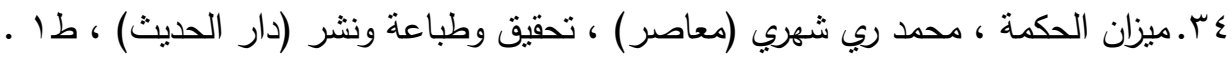

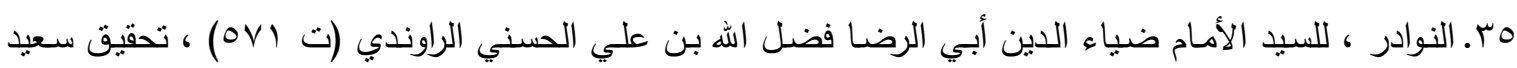

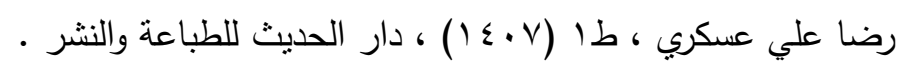

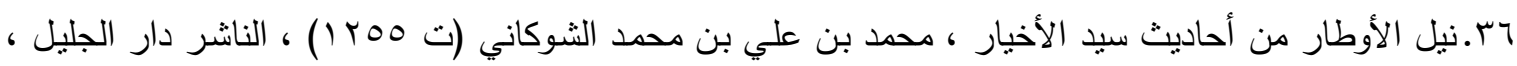

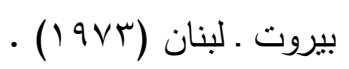

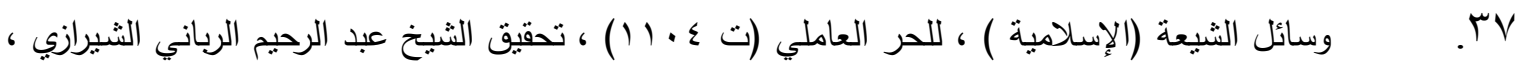

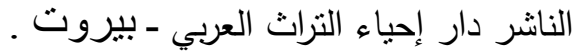

